\title{
Insecticide resistance in the sand fly, Phlebotomus papatasi from Khartoum State, Sudan
}

\author{
Mo'awia Mukhtar Hassan ${ }^{1 *}$, Sally Osman Widaa ${ }^{1,2}$, Osman Mohieldin Osman', Mona Siddig Mohammed Numiary',
} Mihad Abdelaal Ibrahim ${ }^{1}$ and Hind Mohammed Abushama $^{3}$

\begin{abstract}
Background: Phlebotomus papatasi the vector of cutaneous leishmaniasis $(\mathrm{CL})$ is the most widely spread sand fly in Sudan. No data has previously been collected on insecticide susceptibility and/or resistance of this vector, and a first study to establish a baseline data is reported here.

Methods: Sand flies were collected from Surogia village, (Khartoum State), Rahad Game Reserve (eastern Sudan) and White Nile area (Central Sudan) using light traps. Sand flies were reared in the Tropical Medicine Research Institute laboratory. The insecticide susceptibility status of first progeny (F1) of $P$. papatasi of each population was tested using WHO insecticide kits. Also, P. papatasi specimens from Surogia village and Rahad Game Reserve were assayed for activities of enzyme systems involved in insecticide resistance (acetylcholinesterase (AChE), non-specific carboxylesterases (EST), glutathione-S-transferases (GSTs) and cytochrome p450 monooxygenases (Cyt p450).

Results: Populations of $P$. papatasi from White Nile and Rahad Game Reserve were sensitive to dichlorodiphenyltrichloroethane (DDT), permethrin, malathion, and propoxur. However, the P. papatasi population from Surogia village was sensitive to DDT and permethrin but highly resistant to malathion and propoxur. Furthermore, P. papatasi of Surogia village had significantly higher insecticide detoxification enzyme activity than of those of Rahad Game Reserve. The sand fly population in Surogia displayed high AChE activity and only three specimens had elevated levels for EST and GST.

Conclusions: The study provided evidence for malathion and propoxur resistance in the sand fly population of Surogia village, which probably resulted from anti-malarial control activities carried out in the area during the past 50 years.
\end{abstract}

\section{Background}

Leishmaniasis is a vector borne disease caused by a parasite of genus Leishmania. It is considered as a major public health problem, $88^{\text {th }}$ in the world causing morbidity and mortality [1]. The disease also causes serious economic loss and impedes socioeconomic development in many countries [1].

Leishmaniasis is an endemic disease spread over a wide geographical area in Sudan [2,3]. Cutaneous leishmaniasis $(\mathrm{CL})$ occurs in a fluctuating pattern in the country mainly in the west, central and northern parts of Sudan [2]. Whereas, visceral leishmaniasis (VL) is

\footnotetext{
* Correspondence: moawia65@hotmail.com

'Department of Vector Biology and Biomedical Studies, Tropical Medicine Research Institute, National Centre for Research, P. O. Box 1304, Khartoum, Sudan

Full list of author information is available at the end of the article
}

endemic in Savannah areas extending from the Sudanese-Ethiopian border in the east to the banks of the White Nile in the west, and from Kassala in the North towards Blue Nile State to the south with scatter foci in Nuba Mountain and Darfur [3].

The sand fly Phlebotomus papatasi Scopoli (Diptera: Psychodidae) is the principal vector of Leishmania major, the causative agent of CL in Sudan [2]. This species is the most dominant CL vector in the area north of Khartoum where an epidemic of CL had occurred [2]. However, P. papatasi has a wide range of distribution in the country including many parts of the arid areas of Sudan $[2,4]$.

Vector control using insecticide campaigns in many countries have been mainly applied against mosquitoes and so indirectly against other insect vectors. Improper use of insecticide towards vector control has led to the

\section{() Biomed Central}


development of insecticide resistance in tropical countries. However, the development of insecticide resistance in the insect vector threatens the effectiveness of these control measures. The insecticide resistance in sand fly populations has been highlighted by Singh et al. [5] and Kishore et al. [6]. For example in India, studies revealed resistance of sand fly vectors to dichlorodiphenyltrichloroethane (DDT) [5,6]. Currently, studies on insecticide resistance have focused on biochemical and molecular bases, which serve as a means of identifying resistant genotypes in insect populations [7-9]. However, only a few reports worldwide have shown the potential involvement of enzymes in insecticide resistance to sand flies $[7,10]$.

In Sudan, due to intensive use of insecticides by malaria control programmes and in agricultural practice, especially in northern parts of the country, sand flies may have developed resistance to these insecticides. However, to date no single study has been carried out to investigate insecticide resistance in sand flies in the country, although many studies have been conducted on resistance in the malaria vector $[11,12]$. Therefore, this study was carried out to establish baseline data on the susceptibility and/or resistance status of $P$. papatasi to different insecticides.

\section{Methods}

\section{Sand fly collection sites}

In this study, sand flies were collected from three different geographical locations (Figure 1).

Surogia village $\left(15^{\circ} 45^{\prime} \mathrm{N}, 32^{\circ} 15^{\prime} \mathrm{E}\right)$ : the village is located on the eastern bank of the River Nile, about 30 $\mathrm{km}$ north of Khartoum. It is located in the endemic zone of CL [2]. The area is flat and covered by alluvium of still clay and sand deposited by the river. Surogia area experiences a climate of the semi-desert area with three distinct seasons, winter (November-February), summer (March-June), and autumn (July-October). Vegetation in the area is of the desert scrub type dominated by Acacia trees.

White Nile area $\left(32^{\circ} 14^{\prime} \mathrm{E}, 14^{\circ} 72^{\prime} \mathrm{N}\right)$ : the area is located on the western bank of the White Nile about $200 \mathrm{~km}$ south of Khartoum. The area is considered as a revived focus of (Visceral Leishmaniasis) (VL) [13]. Generally, the area is entirely located in the semi-desert dominated by desert scrub vegetation (i.e. Acacia tortilis and Acacia mellifera). This area is inhabited by the villagers and nomads. However, on a clay soil along the river, it was noticed an area of $7 \times 30 \mathrm{~km}^{2}$ occupied by low rainfall savannah vegetation characterized by Acacia seyal/Balanities aegyptiaca thicket.

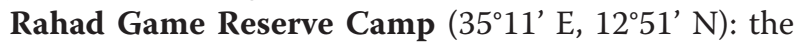
area is located on the western bank of the Rahad river about $40 \mathrm{~km}$ from the main Galgeu Warden Camp (110 $\mathrm{km}$ from the Sudanese-Ethiopian border). The camp is adjacent to Bello village, about $1.5 \mathrm{~km}$. The area is located in the endemic area of VL in eastern Sudan [14]. The ecology of the area was described by Elnaiem et al. [14]. The land is flat, but in many places it is interrupted by the seasonal rivers and tributaries and little ground surface water collection. The soil is mainly chromic vertisol (black cotton soil), with a few fractions of alluvial clays, sandy and silty soil known as "Azaza".

The climate of the area is tropical continental with an estimated annual rainfall of $1000 \mathrm{~mm}$. The year is divided into dry (November-May), and rainy season (June-October). The vegetation of the area is dominated by savannah tree species such as Acacia seyal, A. senegal, Balanites aegyptiaca and Ziziphus spina-christie. The camp is inhabited by 6 people of the DNP Warden Camp. The DNP is protected by Sudanese Civil and Environmental law. Therefore, people are not allowed to carry out any activities (i.e. cultivation and malaria control programmes). However, the villagers near to the camp were allowed to graze cattle, sheep and goats.

\section{Collection and rearing of sand flies}

Wild sand flies were collected from Surogia village and the White Nile area during March-April 2007 and April 2007 from Rahad Game Reserve using light traps set outdoors between 18:00 and 06:00 $\mathrm{Hr}$. In each site sand flies were collected for 8 consecutive nights using 8 light traps where the traps were set at least $20 \mathrm{~m}$ from each other in an area of $150 \mathrm{~m}$ diameter.

In the laboratory, Phlebotomus species were sorted out from the captured sand flies and then transported to Khartoum. The sand flies of each of population were reared and maintained in the insectaries at the Tropical Medicine Research Institute (TMRI), Khartoum as described by Hassan et al. [15]. Briefly, in the laboratory, Phlebotomus sand flies were placed in a clean sand fly cage. Two guinea pigs (1-2 weeks old) were anesthetized (Thiopental at $20 \mathrm{mg} / \mathrm{kg}$-intravenously) and introduced with sand flies in a sand flies cage for 30 minutes. After feeding, blood-engorged sand flies were individually put in oviposition vials lined at the bottom with gypsum (Calcium sulfate) material and covered with mesh. The vials containing females were then maintained at $28-30^{\circ}$ C. After oviposition, females were removed from oviposition vials and were preserved individually in $70 \%$ alcohol for subsequent identification up to the species level by using a proper identification key constructed by Kirk and Lewis [16]. The gypsum material lining the oviposition pots was wetted with distilled water using long syringes. Emerging larvae were then fed with larval food composed of ground rabbit feces. The emerging adult females of $P$. papatasi (F1) were used for susceptibility and biochemical assays. 


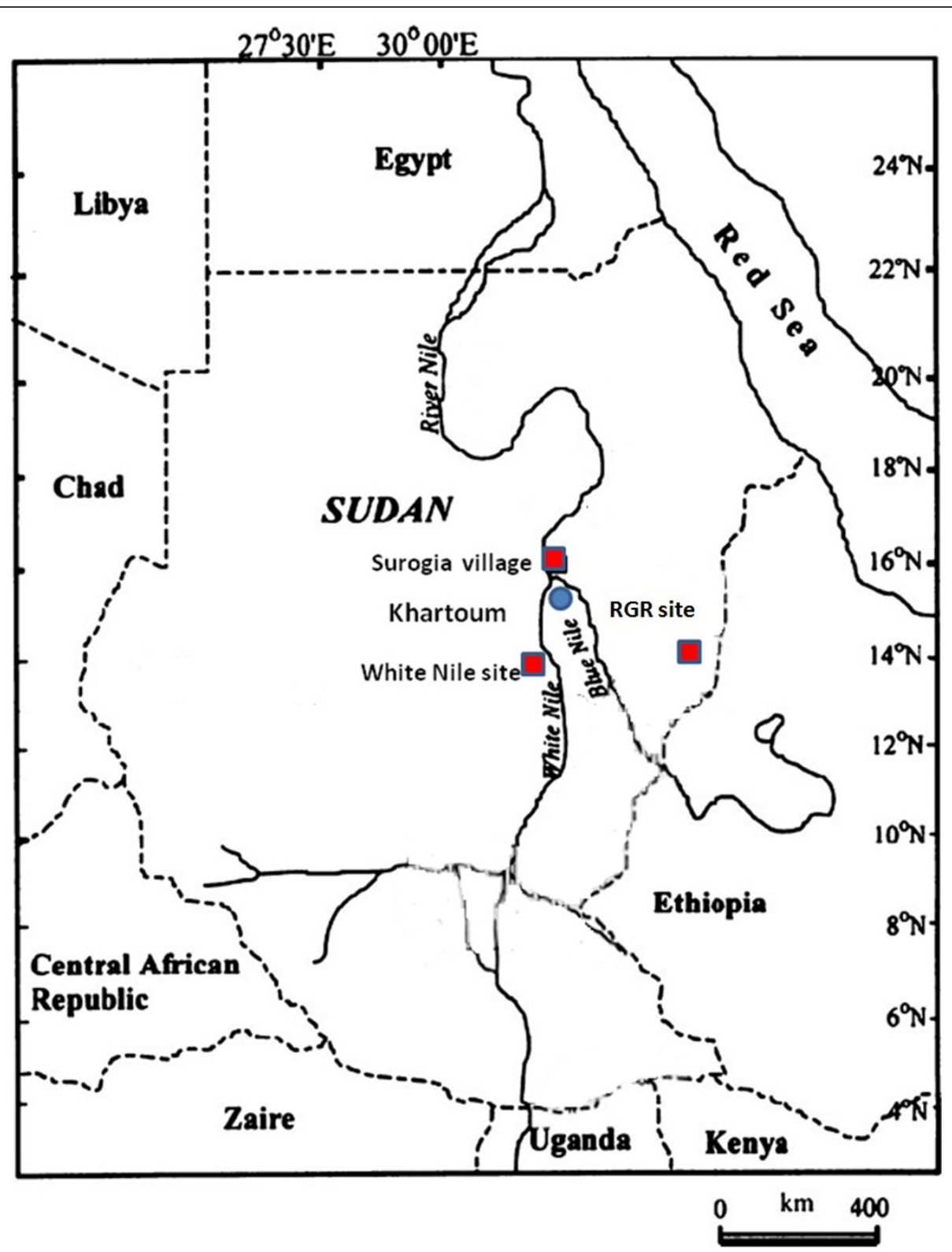

Figure 1 A map of Sudan, showing the location of the study sites (Surogia village, White Nile area and Rahad Game Reserve)

Animals used for sand fly feeding were obtained from an animal house of The Medicinal and Aromatic Plants Research Institute, National Centre for Research. When they were not used in feeding, the animals were kept individually in animal cages (12 sq ft with grids of 2.5 inches) and provided with food and water. Next morning, the animals were returned to the animal house.

The protocol used in this study was designed to follow the standard international guidelines for animal use in experimental research. Also, the protocol was approved by Human and Animal Research Ethics Committee of Tropical Medicine Research Institute, National Centre of Research and Research Ethical Committee of the Federal Ministry of Health (No: FMOH/RD/EC/64/08).

\section{Bioassay tests}

Four insecticides (DDT, permethrin, propoxur and malathion) were used to determine the current status of insecticide resistance in the populations of $P$. papatasi from Surogia village, White Nile area and Rahad Game Reserve. The insecticides used were selected to represent different classes that have been used in Sudan. Standard WHO testing procedures were used to assess insecticide resistance using standard test kit tubes [17] 
under optimum conditions (temperature $26^{\circ} \mathrm{C}$ and 70 $80 \%$ relative humidity).

DDT, permethrin, propoxur and malathion at concentrations $4 \%, 0.75 \%, 0.1 \%$ and $5 \%$ respectively, were used with an exposure time of $60 \mathrm{~min}$. The doses of these insecticides were often used in the past as discrimination doses to separate susceptible from resistant phenotypic populations of sand flies [18]. The test kits were obtained from National Malaria and Leishmaniasis administration, Federal Ministry of Health, Sudan. The test was done in five replicates for each insecticide and one control using oil-treated paper. In each replicate, 20 unfed females were used. The numbers of knockdown and dead flies were recorded after 10, 20, 30, 40, 50 and 60 minutes of exposure. After one-hour exposure to insecticide impregnated papers, the knock-down and the surviving sand flies were transferred to clean holding tubes. The survivors were provided with a $30 \%$ sucrose solution on a piece of cotton. The final mortality was recorded after 24-hours.

\section{Biochemical analysis}

Biochemical analysis was carried out as described by Hemingway [19] and modified by Surendran et al. [7]. Seventy-four and twenty adult fresh females of one day old, from Surogia village and Rahad Game Reserve populations respectively were individually homogenized in $200 \mu \mathrm{l}$ of distilled water in a $1.5 \mathrm{ml}$ eppendorff tube. The aliquots of supernatant from the homogenized flies were used in the four biochemical analyses described below (All readings taken for the replicates of each enzyme as mean optical density values).

\section{Total protein assay}

Total protein of sand flies was analyzed as described by Bradford [20]. The assay was based on the observation of the maximum absorbance of an acidic solution of Coomassie Brilliant Blue G-250 (Sigma Aldrich, USA) shifts from $465 \mathrm{~nm}$ to $595 \mathrm{~nm}$ when binding to protein occurs. The reagent was prepared as described by Bradford [20]. Two replicates of $10 \mu \mathrm{l}$ of each sand fly homogenate were placed in separate wells. $25 \mu \mathrm{l}$ of $\mathrm{NaOH}$ was added to each sample and then $300 \mu \mathrm{l}$ of Bradford reagent was mixed with sand flies homogenates in each well. The microtitre plate was incubated for $5 \mathrm{~min}$ and read at $570 \mathrm{~nm}$ using the ELISA microtitre plate reader. A series of concentrations $(2.5 \mu \mathrm{g}-3000$ $\mu \mathrm{g}$ ) of bovine serum albumin (Sigma Aldrich, USA) were used to prepare a typical standard curve for protein. The standard curve was used to convert the optical density for each sample to a concentration (in $\mu$ g). The concentrations were used to calculate the activity of GST, $\alpha$ and $\beta$-naphthyl acetate.

\section{Acetylcholinesterase (AChE) activity}

Two replicates, each of $25 \mu \mathrm{l}$ of crude homogenate aliquot were transferred to a microtitre plate. Then, $145 \mu \mathrm{l}$ of Triton phosphate buffer (1\% (v/v) Triton X-100 in $0.1 \mathrm{M}$ phosphate buffer $\mathrm{pH} 7.8$ ) was added to each replicate. $10 \mu \mathrm{l}$ of $0.01 \mathrm{M}$ dithiobis 2-nitrobenzoic acid (DTNB) solution in $0.1 \mathrm{M}$ phosphate buffer $\mathrm{pH} 7.0$ and $25 \mu \mathrm{l}$ of the substrate $0.01 \mathrm{M}$ acetylthiocholine iodide (ASChI) (Sigma Aldrich, USA) was then added to one of the replicates to initiate the reaction. Also, $25 \mu \mathrm{l}$ of ASChI containing $0.2 \%(\mathrm{v} / \mathrm{v})$ of the inhibitor propoxur $(0.1 \mathrm{M})$ was added to the second replicate. The kinetic reaction of the enzyme was continuously measured at $405 \mathrm{~nm}$ for $5 \mathrm{~min}$ in an ELISA reader. Then the inhibition percentage of AChE activity due to propoxur, as compared to uninhibited wells was calculated. The residual activity of more than $80 \%$ suggested homozygosity for an altered $\mathrm{AChE}$ whereas values between $60 \%$ and $80 \%$ suggested heterozygosity for sand flies [7].

\section{Non-specific esterase (ETS) activity}

In this assay, two replicates of $20 \mu \mathrm{l}$ of sand fly homogenate aliquot were transferred to separate wells in a microtitre plate. In the first replicate, $200 \mu \mathrm{l} \alpha$-naphthyl acetate solution $(100 \mu \mathrm{l}$ of $30 \mathrm{mM} \alpha$-naphthyl acetate in acetone diluted in $10 \mathrm{ml}$ of $0.02 \mathrm{M}$ phosphate buffer $\mathrm{pH}$ 7.2) was added and $200 \mu \mathrm{l} \beta$-naphthyl acetate solution (prepared as for $\alpha$-naphthyl acetate) was added to the second replicate. The plate was incubated for $15 \mathrm{~min}$ utes at room temperature. Then $50 \mu$ of Fast Blue Stain solution (150 mg Fast Blue in $15 \mathrm{ml}$ distilled water), and $35 \mu \mathrm{l}$ of $5 \%$ sodium lauryl sulphate (SDS) were added to each well. The first column in the microtitre plate containing all the reagents without sand fly homogenate was used as a negative control (Blank). Enzyme activity was read at $570 \mathrm{~nm}$ as an end point reading in an ELISA reader. Ranges of concentrations $(2 \mu \mathrm{g}-500 \mu \mathrm{g}) \alpha$ and $\beta$-naphthyl acetate (Sigma Aldrich, USA) solutions were used to setup standard curves to determine the concentrations of reaction products $\alpha$ and $\beta$-naphthyl acetate in $\mu \mathrm{mol}$ product $\mathrm{min}^{-1} \mathrm{mg}^{-1}$ protein.

\section{Glutathione-S-transferase (GST) activity}

GST activity was assayed by mixing $10 \mu \mathrm{l}$ of homogenate aliquot with $200 \mu \mathrm{l}$ of a substrate solution (95 parts of $10.5 \mathrm{mM}$ reduced glutathione (Sigma Aldrich) in 100 $\mathrm{mM}$ phosphate buffer +5 parts of $63 \mathrm{mM}$ 1-chloro 2,4dinitrobenzene, $\mathrm{CDNB}$, in methanol). The reaction rate was measured at $340 \mathrm{~nm}$ for $5 \mathrm{~min}$ using an ELISA reader. Enzyme activities were recorded as $\mu \mathrm{mol}$ product $\mathrm{min}^{-1} \mathrm{mg}^{-1}$ protein. Then the remaining homogenate was centrifuged for $2 \mathrm{~min}$ at $10,000 \mathrm{~g}$ before aliquots of supernatant were removed for the following assays. 


\section{Cytochrome p450 (Cyt p450) monooxygenases}

$10 \mu \mathrm{l}$ of homogenate was mixed with $80 \mu \mathrm{l}$ of potassium phosphate buffer ( $\mathrm{pH} 7.2)$.

Then $200 \mu \mathrm{l}$ of $6.3 \mathrm{mM}$ tetramethyl benzidine (TMBZ) working solution (0.01 g TMBZ dissolved in $5 \mathrm{ml}$ methanol and in $15 \mathrm{ml}$ of sodium acetate buffer $\mathrm{pH} 5.0$ ) and $25 \mu \mathrm{l}$ of $3 \%(\mathrm{v} / \mathrm{v}) \mathrm{H}_{2} \mathrm{O}_{2}$ solution in a microtitre plate well. After 2 hours incubation at room temperature, the plate was read at $630 \mathrm{~nm}$ as an end point [7] assay using an ELISA reader.

Values were compared with a standard curve of absorbance for known concentrations of cytochrome $\mathrm{C}$ and they were recorded as equivalent units of cytochrome p450 $\mathrm{mg}^{-1}$ protein, for correcting the known haem content of cytochrome $\mathrm{C}$ and $\mathrm{p} 450$.

\section{Results}

Identification of $P$. papatasi

All females used for the establishment of the colonies of sand flies from the three geographic populations were identified morphologically as $P$. papatasi.

\section{Bioassay test}

The results of the insecticide susceptibility tests are shown in table 1. According to the standard WHO [16] procedure, $<80 \%$ mortality 24 -hours post exposure is considered as a strong indicator of resistant strains. In this experiment, discrimination doses previously used for sand flies and different exposure times for resistance and/or susceptibility were used. Phlebotomus papatasi from the Rahad Game Reserve and White Nile area populations were fully susceptible to permethrin, DDT, malathion and propoxur with a mortality level of $100 \%$
24 hours post-exposure. The Population of $P$. papatasi from Surogia village was fully susceptible to permethrin and DDT with mortality rates of $100 \%, 24$ hour post exposure, although the knockdown time value (at $\mathrm{Cl}$ 95\%) obtained with permethrin was relatively high $\left(\mathrm{KDT}_{95}=193.93\right.$ minutes $)$ (Table 1$)$. Malathion and propoxur resistance was detected in $P$. papatasi from Surogia village with the mortality rates of $19 \%$ and $9 \%$ for both insecticides respectively.

\section{Biochemical tests}

The procedures for the biochemical analysis of resistant sand flies [7] were used in this study. The level of enzymes of $P$. papatasi populations from Rahad Game Reserve and Surogia village were compared. Independent student t-tests revealed no significant differences ( $P>0.05$ for all enzymes) in the levels of $\alpha$ and $\beta$ esterase enzymes (EST), glutathione S-transferase (GST) and cytochrome p450 monooxygenase (Cyt p450) between the sand flies of the two populations. However, the propoxur inhibited fractions of Acetylcholinesterase assay (AChE) enzymes showed a significant difference between $P$. papatasi of the two populations $(\mathrm{t}=5.41 ; P$ $=0.004)$.

In this study, $P$. papatasi showed ranges of values for enzyme activities similar to those obtained for susceptible and resistant $P$. argentipes [7]. The levels of AChE activity, after incubation with $0.1 \mathrm{M}$ Propoxur, equivalent to more than $80 \%$ of the activity without propoxur were used as indicator of insensitive AChE. Sand flies of Rahad Game Reserve showed an inhibition fraction ranging from 37.7-53.3\% (Figure 2). Therefore, the specimens of Rahad Game Reserve were used to calculate the

Table 1 Number and percentage of mortality and knockdown time values of female Phlebotomus papatasi from three different geographical areas in Sudan exposed to four different insecticides (WHO kits) after 24-hours exposure.

\begin{tabular}{lllll}
\hline Sand fly population & Insecticide tested & No of tested (replicated) & Mortality (\%) after 24 hours & KDT $_{\mathbf{9 5}}$ (minutes) \\
\hline Surogia & Permethrin (0.75\%) & $100(5)$ & 100 & 193.93 \\
& DDT (4\%) & $100(5)$ & 100 & 84.56 \\
& Malathion (5\%) & $100(5)$ & 19 & $>24 \mathrm{~h}$ \\
& Propoxur (0.1\%) & $100(5)$ & 9 & $24 \mathrm{~h}$ \\
& Control & $100(5)$ & 1 & 20.17 \\
Rahad & Permethrin (0.75\%) & $100(5)$ & 100 & 15.98 \\
Game & DDT (4\%) & $100(5)$ & 100 & 20.69 \\
Reserve & Malathion (5\%) & $100(5)$ & 100 & 22.02 \\
& Propoxur (0.1\%) & $100(5)$ & 100 & 20.16 \\
White Nile & Control & $100(5)$ & 2 & 15.98 \\
area & Permethrin (0.75\%) & $100(5)$ & 100 & 22.02 \\
& DDT (4\%) & $100(5)$ & 100 & 21.08 \\
\end{tabular}

$\mathrm{KDT}_{95}=$ Knockdown time of females (at $\mathrm{Cl}$ 95\%) 


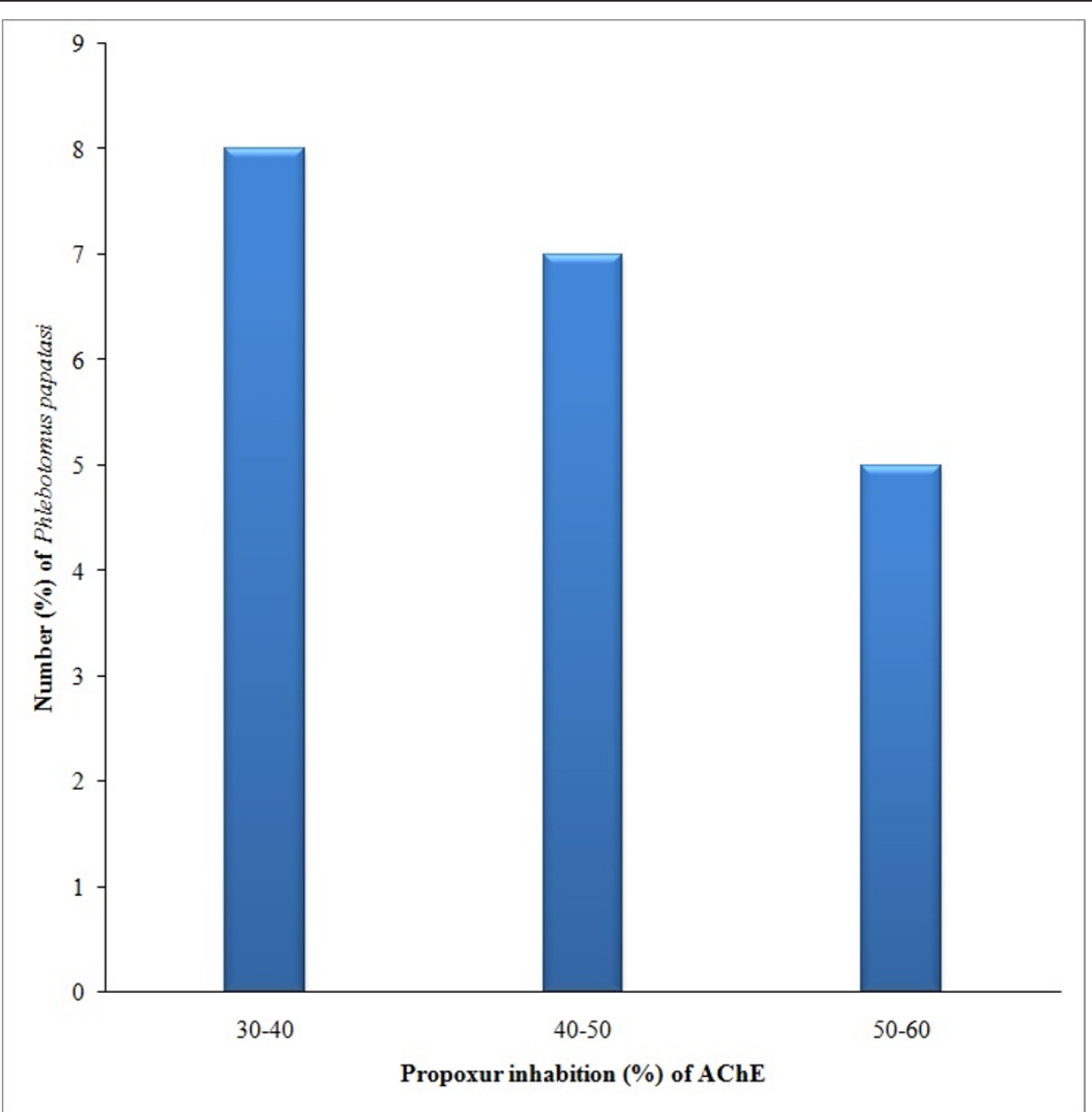

Figure 2 Distribution of Acetylcholinesterase activity in Phlebotomus papatasi from Rahad Game Reserve (Dinder National Park; eastern Sudan) obtained by the biochemical test and used as a cut-of-point for susceptiblity/resistance.

cut-off point for AChE inhibition fraction of the susceptible $P$. papatasi strain. Out of 64 specimens of $P$. papatasi assayed from Surogia village, more than $75 \%$ $(79.7 \%)(\mathrm{n}=51)$ showed insensitive AChE (> 80\% residual activity), suggesting resistance (homogenous resistance). Also, $50 \%$ of the population had an inhibited fraction of more than $100 \%$ (Figure 3 ).

However, $15.6 \%(n=10)$ of the samples had $50-80 \%$ residual AChE activity (suggesting heterogeneous resistance $)$ and $4.7 \%(n=3)$ of the samples had $<50 \%$ residual AChE activity in the (suggesting homogenous susceptibility).

Similarly, specific EST activities of $0.02 \pm 0.007 \mu \mathrm{mol}$ $\mathrm{min}^{-1} \mathrm{mg}^{-1}$ protein and $0.92 \pm 0.08007 \mu \mathrm{mol} \mathrm{min}^{-1} \mathrm{mg}^{-1}$ protein were used as cut-off points for both susceptibility and resistance in $P$. papatasi respectively. In addition, GST specific activities of $0.42 \pm 0.06 \mu \mathrm{mol} \mathrm{min}^{-}$ ${ }^{1} \mathrm{mg}^{-1}$ protein were used as cut-off points for susceptibility in P.papatasi. Phlebotomus papatasi of the Rahad Game Reserve had enzyme activities lower than those levels (EST; $0.0347 \pm 0.003$ and GST; $0.077 \pm 0.002$ $\mu$ mole $\mathrm{min}^{-1} \mathrm{mg}^{-1}$ protein). Almost, $95.9 \%(\mathrm{n}=71)$ of Surogia sand flies showed EST $(0.048 \pm 0.005 \mu$ mole $\mathrm{min}^{-1} \mathrm{mg}^{-1}$ protein $)$ and GST $\left(0.097 \pm 0.01 \mu\right.$ mole $\mathrm{min}^{-1}$ $\mathrm{mg}^{-1}$ protein) activities at or below the elevated values, suggesting susceptibility. However, only three specimens out of 51 specimens with insensitive AChE had elevated values of EST $\left(2.871 \pm 0.49 \mu\right.$ mole $\mathrm{min}^{-1} \mathrm{mg}^{-1}$ protein $)$ and GST $\left(3.44 \pm 0.5746 \mu\right.$ mole $\mathrm{min}^{-1} \mathrm{mg}^{-1}$ protein).

All $P$. papatasi assayed for Cyt $\mathrm{p} 450$ levels had values that fell within the susceptible range.

\section{Discussion}

Insecticide resistance in vectors is a major public health problem especially in the tropical regions. There have been several reports of reductions in sand flies as a collateral benefit of malaria control programmes, although, these flies have developed resistance to insecticide, especially to DDT and less to other insecticides such as malathion and pyrethroids [21-26]. Therefore, it is of 


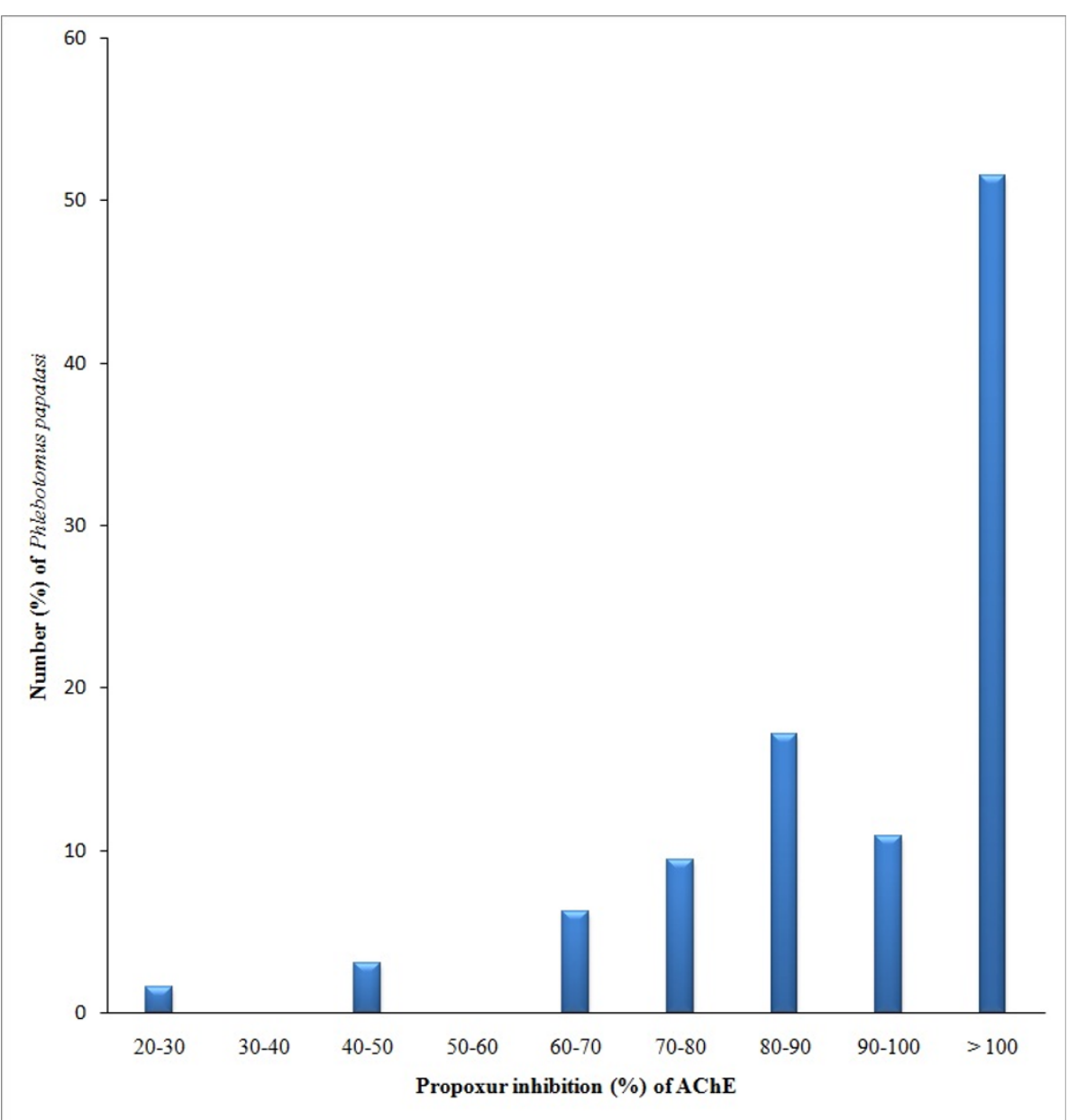

Figure 3 Distribution of Acetylcholinesterase activity in Phlebotomus papatasi from Surogia village (Khartoum State, Sudan) obtained by the biochemical test.

great value in view of control of sand flies and leishmaniasis to establish baseline data and to assess the extent of insecticide susceptibility and resistance in sand fly vectors, in order to design an effective control programme. No studies have previously been done to assess the susceptibility/resistance status of sand flies in the country, therefore, this study was carried out to establish baseline data for future control of sand fly vectors in Sudan.

The concentration of WHO insecticide kits used in this study had been used to test the susceptibility in sand flies and mosquitoes to insecticides [6,27-32]. The results of the susceptibility tests at 10, 20, 30, 40, 50 and 60 minutes of exposure indicated that P. papatasi populations from White Nile area and Rahad Game Reserve were fully susceptible to all insecticides used, whereas; the population of Surogia village was fully susceptible to DDT and permethrin but resistant to malathion and propoxur (Table 1).

These two populations were collected from areas where few or no agricultural practice or malaria control activities applied. The DNP is protected by Sudanese Civil and Environmental law against any human activities, therefore, no cultivation or malaria control programmes are allowed in this area. The collection sites in the White Nile area was from woodland (open area) about $5 \mathrm{~km}$ distance from villages and $3 \mathrm{~km}$ from farms. In contrast, the sand fly population of Surogia village was collected from the Khartoum area where intensive malaria control activities are regularly applied. Developing resistance to malathion and propoxur in the Surogia village population may be attributed to many years of insecticide usage for public health and agricultural purposes in northern Khartoum. No studies on insecticide resistance have been reported from our study sites in White Nile and Rahad River area, however, more recently, a study in Khartoum State revealed resistance in a field population of Culex quinquefasciatus to malathion, lambdacyhlothrin and permethrin [33].

The usage of insecticides for vector control started with benzine hexachloride (BHC) in Sudan back to 
1950s [34]. But due to mosquito, insecticide resistance, BHC was replaced by DDT in 1965 and then to malathion in 1975 [34]. Moreover, due to resistance, malathion was also discontinued in 1979 and replaced by fenitrothion, and later in 1990 to deltamethrin, which is still considered to be effective. No reports are available on the agro-chemical use in Sudan, however, organochlorines and organophosphorus pesticides such as aldrin, chlordane, DDT, dieldrin, heptachlor, hexachlorobenzene and toxaphene have been used in large agricultural schemes e.g. Gezira agriculture scheme.

In this study, biochemical assays as described by Hemingway [19] and modified later by Surendran et al. [7] were used for the analysis of sand flies from two different geographical regions. The results revealed that only three individuals out of 74 sand flies had elevated EST, Cyt p459 and GST activities. This result might support the results shown by the WHO susceptibility test, which revealed that $P$. papatasi is highly susceptible to DDT and permethrin. It is known that these enzymes have been implicated in resistance in many insects of medical importance $[35,36]$, as well as agricultural pests. Therefore, their association with resistance in these sand flies cannot be excluded although only three individuals had elevated level of EST, Cyt p459 and GST activities. For example the presence of few individuals with elevated GST enzymes there may likely be involved in residual resistance due to many years of DDT usage for the mosquito control programme during 1965-1975 [34]. The GSTs have been found to be involved in DDT resistance in sand flies [7] and mosquito species [37], as well as, in the OPs resistance [35].

Furthermore, significant difference in the level of AChE enzyme was observed between the sand fly populations of Rahad Game Reserve and Surogia village. However, AChE insensitivity in the presence of carbomate and propoxur was detected in the P. papatasi population $(79.7 \%)$ from Surogia village. This result might suggest high levels of insecticide resistance in $P$. papatasi due to point mutations in the structural gene (Ace). Point mutation in the ace gene has been found to be associated with high levels of insecticide resistance especially, to OP-resistance and/or carbomates-resistance [38]. In our case, the high levels of resistance in $P$. papatasi could be due to back history of malathion and propoxur application in the anti-malaria vector control activities. In sand flies Lutzomyia longipalpis, insensitive $\mathrm{AChE}$ is caused by point mutations within a single gene (AceI), which led to significant resistance to insecticides [39].

In this study, a major problem was to establish a discriminating concentration or time for the susceptibility test and the values of resistant and susceptible sand flies for biochemical tests. Only a few studies have been carried out to establish discriminating doses for killing susceptible specimens of sand flies $[18,26]$. Also, a single study was carried out to establish cut off values of resistance and susceptibility in sand flies using biochemical analysis [7]. In this study, no resistant reference strain of $P$. papatasi was available, therefore we used discriminating doses and values of resistance and susceptible sand flies in susceptibility tests and biochemical analysis of those used for P. papatasi and P. argentapis [18,26,7]. However, the results obtained in this study suggest that populations of $P$. papatasi can be used in the future to establish cut-off points for susceptible strains in biochemical assays and discriminating concentrations and times for insecticides.

In this study, insecticide resistance in populations of P. papatasi was detected by two methods; WHO insecticide susceptibility tests and biochemical analysis. The insecticide test is often limited by availability of sand fly specimens whereas, the biochemical method is a technique used to determine the mechanism in individual insects; therefore only a small number of insects can be used. The caveat, however, is that, the resistance obtained by measuring enzyme activity, does not always correlate with resistance obtained by the susceptibility test, whereas the susceptibility test results may be an indicator for growing resistance problems, although it does not predict an operational failure of spraying programmes. Because resistance in insect vectors can be caused by various factors including method of application, the size of the insect population and insect genetics (frequencies of alleles involved in resistance) [40]. Moreover, insecticide resistance is likely to result in reduction of the vectorial capacity of the insect by affecting vector longevity, its infectiousness and change in its behaviour [41].

\section{Conclusions}

This study has shown that the populations of $P$. papatasi in Surogia village were resistant to malathion and propoxur but susceptible to DDT and permethrin. However, before concluding that permethrin and DDT can be efficiently used to control sand flies, further studies are needed to determine effective gradients of DDT against sand flies. DDT has adverse human health and environmental effects of exposure. However, the World Health Organization and the Stockholm Convention 2001 have permitted its use only for indoor residual spraying (IRS) to control vector borne diseases [42,43]. Therefore, when using DDT in IRS programs, some operational factors should be considered, these are; adequate supply and distribution of quality DDT, appropriate storage and disposal of insecticides, effectively managed IRS programs, disease surveillance, and evaluation of any adverse effects of DDT to human health and 
the environment, supervision of trained sprayers, raise awareness among spraying personnel and targeted communities on issues relating to DDT use and preventing the dispersion of DDT into agriculture. Also, regular assessment and monitoring of the spread of vector resistance to DDT using conventional bioassays and biochemical assays have an important role in insecticide resistance management and to evaluate the future uses of insecticides for control strategies.

\section{Acknowledgements}

We would like to thank Prof. HAM Kassem of Environmental Basic Sciences Department, Institute of Environmental Studies \& Research, Ain Shams University, Cairo, Egypt for her great help in purchasing reagents and chemicals for biochemical analysis and PCR. Also, our thanks are due to Mr. Suliman A. Gadir for helping in the field. This study was supported by WHO/ TDR-re-entry projects grant ID: A41387 for Dr. M M Hassan and Tropical Medicine Research Institute, National Centre for Research, Sudan.

\section{Author details}

'Department of Vector Biology and Biomedical Studies, Tropical Medicine Research Institute, National Centre for Research, P. O. Box 1304, Khartoum, Sudan. ${ }^{2}$ Blue Nile National Institute for Communicable Diseases, University of Gezira, P. O. Box 101, Wad Madani, Sudan. ${ }^{3}$ Department of Zoology, Faculty of Science, University of Khartoum, P. O. Box 321, Sudan.

\section{Authors' contributions}

MMH designed experiments, coordinated field and lab works, collected and analyzed data, drafted and revised the manuscript; SOW: participated in the field and the lab activities, helped in collected and analyzing the data and drafting the manuscript; OMO: participated in the field and the lab activities, and data analysis; MSMN: participated in the field and lab activities; MAl: contributed to field, lab activities and helped in data analysis; HMA: contributed to design lab analysis and revised the manuscript. All authors have read and agreed with the content of the submitted manuscript

\section{Competing interests}

The authors declare that they have no competing interests.

Received: 17 July 2011 Accepted: 7 March 2012

Published: 7 March 2012

\section{References}

1. World Health Organization: Control of the leishmaniasis. Executive Board $118^{\text {th }}$ session. WHO/EB 118.4 Geneva, Switzerland; 2006.

2. El-Hassan AM, Zijlstra EE: Leishmaniasis in Sudan. Cutaneous leishmaniasis. Trans R Soc Trop Med Hyg 2001, 95(Suppl 1):1-17.

3. Zijlstra EE, El-Hassan AM: Leishmaniasis in Sudan. Visceral leishmaniasis. Trans R Soc Trop Med Hyg 2001, 95(Suppl 1):27-58.

4. Hassan MM, Widaa SO, Ibrahim MA, AbuShara R, Osman MO, Numairy MSM, Khider EM: Studies on ecology of sand flies in Sudan: the First Records of Phlebotomus orientalis and Phlebotomus rodhaini (Diptera: Psychodidae) in Northern Sudan. Ann Trop Med Parasitol 2007 101(7):653-655.

5. Singh R, Das RK, Sharma SK: Resistance of sandflies to DDT in Kala-azar endemic districts of Bihar, India. Bull World Health Organ 2001, 79(8):793.

6. Kishore K, Kumar V, Kesari S, Dinesh DS, Kumar AJ, Das P, Bhattacharya SK: Vector control in leishmaniasis. Indian J Med Res 2006, 123:467-472.

7. Surendran SN, Karunaratne SHP, Adams Z, Hemingway J, Hawkes NJ: Molecular and biochemical characterization of a sand fly population from Sri Lanka: evidence for insecticide resistance due to altered esterases and insensitive acetylcholinesterase. Bull Entomol Res 2005, 95:371-380.

8. Lins R, Souza NA, Peixoto AA: Genetic divergence between two sympatric species of the Lutzomyia longipalpis complex in the paralytic gene, a locus associated with insecticide resistance and lovesong production. Mem Inst Oswaldo Cruz 2008, 103(7):736-740.
9. Liu Y, Zhang H, Qiao C, Lu X, Cui F: Correlation between carboxylesterase alleles and insecticide resistance in Culex pipiens complex from China. Parasit Vectors 2011, 4:236.

10. El-Sayed SM, Hemingway J, Lane RP: Susceptibility baselines for DDT metabolism and related enzyme systems in the sandfly Phlebotomus papatasi (Scopoli) (Diptera: Psychodidae). Bull Entomol Res 1989, 79:679-684.

11. Himeidan YE, Abdel Hamid MM, Jones CM, Ranson H: Extensive permethrin and DDT resistance in Anopheles arabiensis from eastern and central Sudan. Parasit Vectors 2011, 4:154.

12. Abdallah H, Matamboa TS, Koekemoera LL, Mnzavae AP, Hunta RH, Coetzeea M: Insecticide susceptibility and vector status of natural populations of Anopheles arabiensis from Sudan. Trans R Soc Trop Med Hyg 2008, 102:263-271.

13. Khalil EA, Musa AM, Elgawi SH, Meshasha A, Gamar Eldawla I, Elhassan MO, Eljaleel KA, Younis BM, Elfaki ME, Elhassan AM: Revival of a focus of visceral leishmaniasis in central Sudan. Ann Trop Med Parasitol 2008, 102(1):79-80.

14. Elnaiem DA, Hassan KH, Ward RD: Phlebotomine sandflies in a focus of visceral leishmaniasis in a border area of eastern Sudan. Ann Trop Med Parasitol 1997, 91:307-318.

15. Hassan MM, Elhassan AM, Musa AM, Osman OF, El Raba'a FMA, Balkew M, Elhassan IM: Establishment and maintenance of a laboratory colony of the sandfly Phlebotomus orientalis (Diptera: Psychodidae) the vector of visceral leishmaniasis in Sudan. Khartoum Med J 2010, 3(2):420-424.

16. Kirk R, Lewis DJ: The phlebotomine of the Ethiopian region. Trans $R$ Entomol Soc London 1951, 102:383-510.

17. World Health Organization: Test procedures for insecticide resistance monitoring in malaria vectors, bio-efficacy and persistence of insecticide on treated surfaces. WHO/CDS/MAL/98.12 Geneva, Switzerland 1998.

18. Fahmy AR, Khater EIM, El Sawaf B, Shehata M: Insecticide susceptibility status of field populations of sandfly in the Sinai Peninsula, Egypt. 1996, WHO/LEISH/96.38.

19. Hemingway J: 1998 , WHO/CDS/MAL/98.6.

20. Braford MM: A rapid and sensitive for the quantitation of microgram quantities of protein utilizing the principle-dye binding. Anal Biochem 1976, 72:248-254.

21. Mukhopadhyay AK, Kumar K, Rahman SJ: Host preference of phlebotomine sandflies in and around Delhi. J Comm Dis 1987, 19(4):408-411.

22. Amalraj DD, Sivagnaname N, Srinivasan R: Susceptibility of Phlebotomus argentipes and P. papatasi (Diptera: Psychodidae) to insecticides. J Commun Dis 1999, 31(3):177-180.

23. Tetreault GE, Zayed AE, Hanafi HA, Beavers GM, Zeichner BC: Susceptibility of sand flies to selected insecticides in North Africa and the Middle East. J Am Mosa Control Assoc 2001, 17(1):23-27.

24. Morali M, Cianchi T, Bianchi R, Khoury C: Testing insecticide susceptibility of Phlebotomus perniciosus and P. papatasi (Diptera: Psychodidae) in Italy. Ann Ist Super Sanità 2002, 38(4):419-423.

25. Alexander B, Maroli M: Control of phlebotomine sandflies. Med Vet Entomol 2003, 17:1-18.

26. Dinesh DS, Das ML, Picado A, Roy L, Rijal S, Singh SP, Das P, Boelaert M, Coosemans M: Insecticide Susceptibility of Phlebotomus argentipes in Visceral Leishmaniasis Endemic Districts in India and Nepal. PLoS Negl Trop Dis 2010, 4(10):e859.

27. Ranson $\mathrm{H}$, Abdallah H, Badolo A, Guelbeogo WM, Kerah-Hinzoumbe C Yangalbe-Kalnone E, Sagnon N, Simard F, Coetzee M: Insecticide resistance in Anopheles gambiae: data from the first year of a multi-country study highlight the extent of the problem. Malar J 2009, 8:299.

28. Balkew M, Ibrahim M, Koekemoer LL, Basil D, Brooke BD, Engers $H$, Aseffa A, Gebre-Michael T, Elhassen I: Insecticide resistance in Anopheles arabiensis (Diptera: Culicidae) from villages in central, northern and south west Ethiopia and detection of $k d r$ mutation. Parasit Vectors 2010, 3:40.

29. Hunt RH, Fuseini G, Knowles S, Stiles-Ocran J, Verster R, Kaiser ML, Choi KS, Koekemoer LL, Coetzee M: Insecticide resistance in malaria vector mosquitoes at four localities in Ghana, West Africa. Parasit Vectors 2011, 4:107.

30. Kamgang B, Marcombe S, Chandre F, Nchoutpouen E, Nwane P, Etang J, Corbel V, Paupy C: Insecticide susceptibility of Aedes aegypti and Aedes albopictus in Central Africa. Parasit Vectors 2011, 4:79. 
31. Hunt RH, Edwardes M, Coetzee M: Pyrethroid resistance in southern African Anopheles funestus extends to Likoma Island in Lake Malawi. Parasit Vectors 2010, 3:112.

32. Kloke RG, Nhamahanga E, Hunt RH, Coetzee M: Vectorial status and insecticide resistance of Anopheles funestus from a sugar estate in southern Mozambique. Parasit Vectors 2011, 4:16.

33. Jamal AE, Nugud AD, Abdalmagid MA, Bashir Al, Elnaiem IH: Susceptibility of Culex quinquefasciatus Say (Diptera: Culicidae) in Khartoum locality (Sudan) to Malathion, Temephos, Lambdacyhalothrin and Permethrin insecticides. Sudanese J Pub Health 2010, 6(2):56-62.

34. El Gadal AA, Haridi AA, Hassan FT, Hussein H: Malaria control in the Gezira-Managil Irrigated Scheme of the Sudan. J Trop Med Hyg 1985, 88(2):153-159.

35. Hemingway J, Miyamoto J, Herath PRJ: A possible novel link between organophosphorus and DDT insecticide resistance genes in Anopheles: supporting evidence from fenitrothion metabolism studies. Pesticide Biochem Physiol 1991, 39:49-56.

36. Berge JB, Feyereisen $R$, Amichot $\mathrm{M}$ : Cytochrome $\mathrm{p} 450$ monooxygenases and insecticide resistance in insects. Philos Trans R Soc Lond B Biol SCi 1998, 353:1701-1705.

37. Prapanthadara LA, Kuttastep S, Hemingway J, Ketterman AJ: Characterization of the major form of glutathione transferase in the mosquito Anopheles dirus A. Biochem Soc Trans 1995, 23(1):81S.

38. Weill M, Lutfalla G, Mogensen K, Chandre F, Berthomieu A, Berticat C, Pateur N, Philips A, Fort P, Raymond M: Insecticide resistence in mosquito vectors. Nature (Lond.) 2003, 423:136-137.

39. Coutinho-Abreu IV, Balbino VQ, Valenzuela JG, Sonoda IV, RamalhoOrtigão JM: Structural characterization of acetylcholinesterase 1 from the sand fly Lutzomyia longipalpis (Diptera: Psychodidae). J Med Entomol 2007, 44(4):639-650.

40. World Health Organization: Resistance of vectors of disease to pesticides. $5^{\text {th }}$ report of expert committee on vector biology and control. WHO Tech Rep Ser 655 Geneva Switzerland; 1980.

41. Rivero A, Vézilier J, Weill M, Read AF, Gandon S: Insecticide Control of Vector-Borne Diseases: When Is Insecticide Resistance a Problem? A review, PLoS Pathog 2010, 6(8):e1001000.

42. United Nations Environment Programme: Stockholm convention on persistent organic pollutants (POPs). UNEP/Chemicals/2002/9 Geneva, Switzerland; 2002.

43. World Health Organization: The Use of DDT in Malaria Vector Control. WHO Position Statement. WHO/HTM/GMP/2007 Geneva Switzerland; 2007.

doi:10.1186/1756-3305-5-46

Cite this article as: Hassan et al:. Insecticide resistance in the sand fly, Phlebotomus papatasi from Khartoum State, Sudan. Parasites \& Vectors 2012 5:46.

\section{Submit your next manuscript to BioMed Central and take full advantage of:}

- Convenient online submission

- Thorough peer review

- No space constraints or color figure charges

- Immediate publication on acceptance

- Inclusion in PubMed, CAS, Scopus and Google Scholar

- Research which is freely available for redistribution 